\title{
Significado y tradición de un relato mítico. Los orígenes de la Casa de Haro
}

Entre los diversos materiales que reúne el título IX del Livro de linbagens - compuesto entre 1340 y 1344 por el conde de Barcelos, y refundido en 1360-1365 y 1380-1383- destaca un corpus de narraciones legendarias acerca de los fundadores del linaje de Haro y del señorío de Vizcaya.

Según cuenta la segunda de ellas, Don Diego López y la Dama, Diego López, cuarto señor, llevó a vivir consigo a una bella desconocida que encontró en el campo, tras comprometerse a respetar cierta prohibición que ella le impuso. Tuvieron un hijo, Íñiguez Guerra, y una hija. Durante un banquete, don Diego transgredió la prohibición, y su esposa regresó para siempre a las montañas, llevándose a la hija. Tiempo después, el señor de Vizcaya, que había conseguido quedarse con el hijo, fue apresado por los moros. La historia de Iñiguez Guerra y la Dama relata cómo Íñiguez Guerra - quinto señor, tras morir don Diegoacudió a su madre, que no era sino el Culebro de Vizcaya, para solicitar su ayuda. Con el caballo que ella le donara, Pardalo, pudo "volar» hasta Toledo, liberar a su padre y salir victorioso de todas las batallas en que después participó. Desde entonces hasta la muerte de Juan el Tuerto (1326), los señores de Vizcaya ofrecían sacrificios a su antepasada en Busturia. Cuando no lo hacían, tanto ellos como el señorío sufrían las agresiones de aquella, que a veces aparecía en las aldeas en figura de escudero.

Ya desde finales del siglo XV, la mayoría de los autores que han tratado de estas narraciones han coincidido en establecer, desde perspectivas muy distintas, determinadas conexiones entre ellas y otros «casos» y relatos, que forman un conjunto muy amplio y heterogéneo. Por ello, como condición previa e indispensable para el análisis sincrónico y paradigmático de cualquier estructura narrativa tradicional, es necesario comenzar adoptando ciertos criterios de selección para precisar los límites del caótico corpus que, de lo contrario, podría presentarse. Limitamos su alcance a dos grupos de narraciones:

I. Por lo que se refiere a los distintos tipos de relaciones entre seres sobrenaturales y humanos:

- Los casos alusivos a la concepción de personajes ilustres, gracias a la unión de un mortal con un ser sobrenatural. 
- Dentro de ellos, el grupo de los que responden a un elemental programa narrativo, definido inicialmente por la desunión de un ser sobrenatural femenino y un varón mortal, la unión de ambos en la sociedad humana, y su desunión final, motivada por el desplazamiento del ser sobrenatural a su mundo.

A partir de algunos relatos que obedecen a este modelo, Jean d'Arras compuso, casi medio siglo después de que don Pedro terminara su nobiliario, Le Livre de Mélusine' (1387-1394). La temprana y extraordinaria difusión de esta obra ha hecho que la historia de Melusina sea la más conocida de todas las de ese conjunto, y, por extensión, su nombre se ha hecho genérico.

Consideramos que las realizaciones conocidas de esta leyenda son expresiones de un modelo abierto y dinámico. Así, denominamos leyenda melusiniana a ese "modelo» virtual, a que responden todos y cada uno de esos relatos (versiones), y versiones melusinianas, a cada una de las manifestaciones, hasta cierto punto diferentes, de ese modelo.

De acuerdo con estos criterios, seleccionamos, en primer lugar, un conjunto de cuarenta versiones melusinianas, clasificadas en tres grupos ${ }^{2}$.

1. Versiones de Vizcaya, Galicia y Castilla, relativas a los linajes de Haro, Mariño y Manrique, de los siglos XIV al XVI, y XIX.

2. Versiones europeas (procedentes de Francia, Alemania, Gran Bretaña e Italia), de los siglos XII al XIV, XVI-XVII, y XX.

3. Versiones vascas, asturianas y catalanas, recogidas de la tradición oral y publicadas en la época contemporánea.

II. El segundo corpus está formado por otras narraciones legendarias sobre los Haro, señores de Vizcaya, contenidas en el mismo título IX, y en la Crónica de Vizcay'a (1454) y Las Bienandanzas e Fortunas ${ }^{4}$ (1.471-1.476), de Lope García de Salazar. Se trata de:

- Dos versiones de La concepción de Zuría.

- Dos versiones de La batalla de Arrigorriaga. La elección del prime'r señor de Viscaj'a.

- La madrastra de Iñigo Esquerra.

Jean d'Arras, Mélusine. Roman du xir siècle (Dijon: Université de Dijon, 1932).

Para éste u otro tema de los tratados en el presente artículo, ver J. Ramón PRIFT() LASA, Las levendas de los señores de Vizcaya y la tradición melusiniana (Madrid: Universidad Complutense) (en prensa).

Lope (iarcía de SAlazar, "Crónica de Vizcaya», en Las dos primeras crónicas de Viacaya, ed. de Sabino Aguirre Gandarias (Bilbao: Caja de Ahorros Vizcaína, 1986).

+ Lope Garcia De Salazar, Las Bienandanzas e Fortunas, ed. de Ángel Rodríguez Hertero (Bilbao: Diputación de Vizcaya, 1967), IV. 
Basándose, en parte, en anteriores aportaciones, el Seminario Menéndez Pidal propone un modelo teórico para analizar y describir estructuras narrativas abiertas '. La concepción misma de este modelo y su comprobada validez y eficacia para un tipo de relatos - los romances-, relativamente «cercano» a los seleccionados, aconsejan su aplicación para el análisis de éstos; aplicación que debe ser más «adaptada» que «automática»: los relatos romancísticos poseen ciertos rasgos específicos - como su discurso doblemente articulado, prosódica y dramáticamente-, de los que no participan los nuestros.

De forma resumida, consideramos, como C. Segre ", que los relatos se hallan articulados en cuatro niveles de organización, que denominamos Discurso, Intriga, Fábula y Modelo actancial. Pero, a diferencia de él, planteamos que la relación entre ellos es, en cada caso, la de significante/significado de un signo lingǘstico.

Del conjunto de informaciones proporcionadas por el análisis de los distintos contextos en que han sido insertadas las versiones melusinianas, son significativas las referentes a algunos aspectos ilustrativos del comportamiento diacrónico de la leyenda: sus diferentes procedencias, procesos de transmisión o funciones; y, en relación con ellos, las calificaciones que, a priori o a posteriori, recibe el ser sobrenatural.

La gran diversidad que se advierte en sus niveles superficiales se justifica en virtud de la apertura, propiedad característica de los objetos pertenecientes a la cultura tradicional, que permite adecuar cada uno de ellos a finalidades e intereses determinados, en diferentes situaciones. En este sentido han tenido notable incidencia las circunstancias espaciotemporales en que se han recogido las versiones, su contexto, procedencia y proceso de transmisión y elaboración; y, sobre todo, las distintas finalidades a que han servido a lo largo de su historia.

En el nivel del discurso ofrecen una extensa gama de modalidades, que abarca desde la presentación casi puramente «referencial» hasta la composición literaria. A pesar de que muchas de las versiones publicadas por folkloristas contemporáneos ofrecen un alto grado de fidelidad y respeto a la tradición oral, pueden observarse rasgos que permiten diferenciar entre las transcripciones exactas y las alteradas mediante intervenciones del editor (presentadas en forma de resumen, con rasgos

5 Diego Catalán et al., Catálogo General del Romancero (Madrid: Seminario Menéndez Pidal-Gredos, 1984), I.

6 Cesare SEGRE, Las estructuras y el tiempo. Narración, poesía, modelos (Barcelona: Planeta, 1976). 
lingüísticos ajenos al lenguaje narrativo tradicional, etc.). Las que han ido circulando por vía erudita han sufrido manipulaciones más importantes.

La mayoría de ellas están en tercera persona y en prosa, pero también las hay en primera persona, en verso, o con versos intercalados, aparentemente procedentes de la tradición oral, puestos en boca de los seres sobrenaturales. Las proporciones [narración (predominante) / diá$\log 0]$ y [discurso directo / indirecto] varían sensiblemente de unas versiones a otras. Con excepción de las «literarias», las intervenciones de los personajes se limitan, a lo sumo, a tres situaciones:

- Sedución y formalización del contrato matrimonial entre el mortal y la mujer sobrenatural.

- Advertencias que el mortal recibe, a través de un informante, acerca del peculiar comportamiento que su esposa observa, tras la unión, en la sociedad humana.

- Intervenciones de la mujer sobrenatural antes de abandonar la sociedad humana.

Entre las consecuencias derivadas de los distintos fenómenos que afectan al nivel de la intriga (omisión y adición de funciones; alternativas y funciones que cambian de sujeto; etc.), llama la atención el reducido número de funciones que se manifiestan explícitamente en todas las versiones, con respecto al total:

- Un mortal lleva a una mujer sobrenatural a la sociedad humana.

- La mujer observa una conducta sospechosa.

- El mortal es impulsado a romper el pacto.

- El mortal rompe el pacto.

- La mujer sobrenatural manifiesta su condición oculta.

La estructura fabulística de la leyenda responde al siguiente modelo:

1. Un mortal se desplaza al mundo sobrenatural.

2. Una mujer sobrenatural seduce al mortal.

3. La mujer admite que la unión con el mortal se realice en la sociedad humana.

4. La desconocida exige respeto al secreto que guarda sobre su identidad.

5. El mortal la lleva a la sociedad humana.

6. La esposa pare un hijo.

7. La mujer sobrenatural observa una conducta sospechosa, y su esposo es impulsado a romper el pacto.

8. El mortal rompe el pacto: la mujer sobrenatural manifiesta su condición oculta y se desplaza a su mundo. 
9. La situación del mortal sufre una degradación, pero la mujer ayuda a sus descendientes, con quienes mantiene el pacto.

La leyenda muestra cómo la calificación del mortal como SujetoHéroe está subordinada al cumplimiento de sus funciones de proveedor y protector con respecto a la comunidad humana que le ha sido encomendada. En este sentido, el ser sobrenatural desempeña las funciones de Ayudante y Oponente: proporciona al mortal los medios materiales para asegurar la provisión de su grupo - en especial mediante el nacimiento de una descendencia-, pero su conducta supone una transgresión grave de ciertas normas del código vigente en la sociedad en que se ha integrado. El mortal, protector de su comunidad, desenmascara el perfil oculto de su esposa y provoca el retorno de ésta a su mundo. Simultáneamente, surge un conflicto de competencia entre el padre y el primogénito, que la mujer sobrenatural dirime: aquél pierde el fundamento de su prosperidad, ésta mantiene su pacto con su hijo (nuevo Sujeto-Héroe) y con sus descendientes.

Otro perfil necesario, e inseparable del anterior, en el análisis del relato mítico consiste en observar cómo su núcleo toma cuerpo, se manifiesta y se difunde a lo largo de los tiempos. Se trata, en este caso, de rastrear sus diferentes manifestaciones desde su inclusión en el Livro de linbagens y los cambios de enfoque que ha sufrido su análisis, en función de los contextos culturales a que se ha incorporado.

Debemos comenzar por la «reconstrucción» del proceso de composición del título IX, lo cual exige analizar sus sucesivas secuencias generacionales y la procedencia de los materiales utilizados para su redacción. La articulación de las conclusiones de dicho análisis con diversas noticias de carácter histórico, relativas al linaje de Haro y al señorío de Vizcaya, permite precisar la situación en que nuestro relato fue incorporado a la genealogía familiar, tal como figura en el título IX del Livro de linhagens.

Tal genealogía pudo tener su origen en circunstancias análogas a las de otros linajes de la nobleza europea durante la Edad Media. Parece que su primitivo núcleo estuvo constituido por un escueto necrologio del monasterio riojano de San Millán de la Cogolla. Necrologio iniciado en la última década del siglo XI, tras la muerte de Lope fñiguez, primer «señor» del título IX cuya identificación histórica no plantea dificultades, en 1093. Hasta el último cuarto del siglo XI, la familia condal, el territorio que gobernaba y el monasterio donde debió de tener su primitivo panteón estuvieron vinculados al reino de Navarra, cuna de importantes testimonios genealógicos de la Edad Media peninsular. 
Entre finales del siglo XII y principios del XIII, las historias de los Haro y de Vizcaya atraviesan uno de sus momentos más decisivos y gloriosos. Vizcaya reúne todas las piezas territoriales que la caracterizarán en adelante; a los Haro, tras haber sido separados durante parte del siglo XII del gobierno de Vizcaya, se les reconoce la titularidad del señorío, que queda adscrito hereditariamente al linaje. Entre las circunstancias que pudieron influir en esta modificación estatutaria están la tradicional fidelidad de la familia a los monarcas castellanos y el interés de aquélla por el dominio de esta zona del litoral cantábrico, que, por su estratégica situación en el eje atlántico de relaciones entre la Península y otros países europeos, atravesaba por un momento de reactivación económica.

El principal responsable de esta «refundación», física e institucional, del señorío es Diego López de Haro II (1170-1214), hábil político y singular héroe legendario. Estuvo relacionado, por razones de parentesco, con grandes familias de la aristocracia castellana y europea (Lara, Manrique, Narbona), algunas de las cuales fueron titulares de los llamados señoríos jurisdiccionales calificados (Molina, Albarracín y Cameros, como Vizcaya). Al igual que sus sucesores y otros magnates de su tiempo, tuvo su propia corte de juglares y trovadores.

Su época señala el comienzo de la etapa de esplendor de la Casa, y como tal sería recordada en generaciones posteriores. Debido al importantísimo influjo que ejerció, o a su propia iniciativa, se fueron incorporando a la historia familiar, iniciada en el necrologio emilianense, los mencionados relatos y otras noticias genealógicas, que componen lo que denominamos "período fundacional» de la estirpe y del señorío. Relatos y noticias que transmiten cuatro principios concernientes a la calificación de la Casa, a su relación con el territorio y a las pretensiones que sobre él puedan tener poderes ajenos: milia.

- Legitimidad, prestigio, antigüedad y origen sobrenatural de la fa-

- Fidelidad de los señores a sus antepasados.

- Calificación heroica del linaje, derivada de su origen y de esa fidelidad, demostrada en distintas ocasiones.

- Derechos de jefatura y función protectora con respecto al señorío.

Su propósito no es otro que el de legitimar el poder familiar y afianzar su prestigio frente a la autoridad monárquica, a la aristocracia y al propio señorío. Los encargados de su redacción, dependientes de la corte señorial, utilizaron los procedimientos entonces habituales en la composición de las Genealogías señoriales europeas, entre los que interesa destacar la apropiación de tradiciones populares para explicar 
y exaltar los orígenes del linaje. Tales procedimientos responden al marco general que define las pautas culturales de la nobleza europea en este período, donde ejercieron notable influjo las cortes de Leonor de Aquitania y de los Plantagenet, a cuyas familas (Aquitania, Anjou, Plantagenet), como a la de los Manrique -emparentados con los Haro- se atribuyeron los mismos orígenes que a la de los señores de Vizcaya.

Las relaciones familiares, políticas y culturales tanto de la corte de Alfonso VIII -donde Diego López II ocupó importantes cargos y puestos de distinción - como de los Haro y sus parientes con ese ambiente fueron intensas. El período histórico coincide con la que podemos denominar época dorada de la leyenda: precisamente en los años finales del siglo XII y primeros del XIII se advierte un creciente interés hacia ella por parte de determinados sectores de la nobleza y del clero, que la utilizan con fines genealógicos o moralizantes.

Parece que la documentación genealógica sobre los Haro que manejó el conde de Barcelos no era anterior al último cuarto del siglo XIII. Pudo tener acceso a ella, junto a testimonios relativos a las familias de Lara y Castro, gracias a su amistad con los Lara: entre 1334 y 1350 Juan Núñez de Lara era, por su matrimonio con María Díaz de Haro II, señor de Vizcaya. El tratamiento encomiástico que recibe este linaje, especialmente en las últimas generaciones del título IX, contrasta con la desoladora visión que se ofrece de los Haro y de Vizcaya en el mismo período, de manera que el linaje de Lara aparece como el nuevo protector que el señorío necesita.

En aquel momento histórico, el éxito del Livro estaba asegurado por las razones de carácter práctico enumeradas en su prólogo. En siglos posteriores continuó gozando de gran autoridad y prestigio; prueba de ello es el elevado número de manuscritos de los siglos XVI y XVII, conservados en distintos archivos y bibliotecas de Portugal, España, Francia, Inglaterra, etc. ?

Sin embargo, aunque interesaba aprovechar su valioso contenido histórico-genealógico, era necesario reconvertirlo en instrumento útil, asequible, para las aplicaciones que en aquel momento eran prioritarias. Las transformaciones, de diversos alcances, producidas desde mediados del siglo XIV habían provocado diferentes correlaciones de fuerzas en

Los textos de los veintisiete manuscritos que he examinado, ocho en portugués y diecinueve en castellano, dependen, en última instancia, del transmitido en el códice del Archivo de la Torre do Tombo (Lisboa), que reproduce un arreglo realizado pocos años después de la redacción del tratado, y del que se sacó una copia durante la incorporación de Portugal a la Corona española para ser depositada en El Escorial. 
la estructura del poder. Habían variado muchas circunstancias: la composición del estamento nobiliario, cuya historia recordaban las Genealogías, con la ascendencia de unas Casas y el declive de otras; sus aspiraciones y privilegios económicos y sociales; las tácticas de conquista y defensa de los mismos; las relaciones entre los distintos linajes y las que éstos, en conjunto y por separado, mantenían con la Corona; etc. El Nobiliario de don Pedro, como otros tratados genealógicos, debió servir, por tanto, a objetivos e intereses distintos a los propuestos en el momento de su composición: tuvo una utilización jurídica, en alegaciones y litigios relacionados con las formas de movilidad social en el Antiguo Régimen, y fue aprovechado como fuente de información para estudios de carácter histórico-genealógico.

Algunas de las consecuencias más significativas del proceso de actualización al que, por esta razón, fue sometido son:

- Dos traducciones castellanas, realizadas a finales del siglo $\mathrm{XV}$ o principios del XVI; la versión más literal y arcaica, en cuanto a estructuras sintácticas y vocabulario, fue la que mayor difusión tuvo.

- Alteraciones textuales debidas a la influencia de aclaraciones o datos suministrados directamente por sus anotadores, o indirectamente por las fuentes que éstos consultaron.

- Tendencias de aproximación a modelos lingüísticos más cercanos, sin alterar sustancialmente el contenido.

- Realización de adaptaciones, manuscritas e impresas: especialmente la edición portuguesa de Juan Bautista Labaña (Roma, 1640) ${ }^{8}$, y la castellana de Manuel de Faria y Sousa (Madrid, 1646) ?. En todas se observa un mismo criterio: la tendencia a conservar y ordenar, casi exclusivamente, las líneas genealógicas de los linajes y sus relaciones de parentesco. Sólo se guarda memoria de algunos relatos, o de datos procedentes de ellos, aprovechables para explicar situaciones presentes o acontecimientos del pasado que, en función de alguno de los objetivos mencionados, seguían teniendo interés.

Así, en el título IX las adaptaciones mantienen, aunque resumida, la narración inicial (La elección de Froom y la batalla de Arrigorriaga), y suprimen las relativas a Diego López e Íñiguez Guerra, de quienes sólo se conserva la escueta noticia de la sucesión hereditaria como señores de Vizcaya, y, en algún caso, una referencia al cautiverio del

${ }^{8}$ Nobiliario de D. Pedro, conde de Barcelos, bijo del rey D. Dionís de Portugal (Roma, 1640).

- Nobiliario del conde de Barcelos don Pedro, bijo del rey don Dionís de Portugal (Madrid, 1646). 
primero en Toledo, dato que para algunos continuaba teniendo interés histórico.

Las narraciones no servían a ninguno de los objetivos aludidos: había perdido vigencia la finalidad por la que se habían incluido, hacía al menos doscientos años, en el título IX. Si pretendían justificar la instalación de los Haro en el señorío, la titularidad de éste era ostentada, personal e ininterrumpidamente, desde 1379 por los monarcas castellanos. En los siglos XVI y XVII tal situación se entendía como un derecho hereditario; nadie discutía su legitimidad, aunque hubiese distintas interpretaciones de la forma de ejercerlo.

Además, desde el punto de vista historiográfico la aceptación de esta parte del título, como otros testimonios sobre la historia de Vizcaya y de sus señores, tropezaba con serias objeciones. Por un lado, las significativas discrepancias existentes entre las fuentes que, además del Livro de linhagens, trataban estos asuntos (historias generales, crónicas, relaciones genealógicas, y, sobre todo, los tratados de Lope García de Salazar). Por otro, un factor externo de carácter historiográfico: el creciente interés por una validación más crítica de la información aportada en las fuentes, sobre todo en ciertas fábulas locales, por parte de algunos historiadores desde el Renacimiento. La presencia de elementos maravillosos en las narraciones fue un factor decisivo para rechazarlas.

Cronistas y eruditos de la época, como Pedro Jerónimo de Aponte " Juan Salgado de Araujo ${ }^{11}$ y Luis de Salazar y Castro ${ }^{12}$, aluden a la falta de rigor del conde de Barcelos, quien tomó por sucesos históricos lo que sólo eran "patrañas» o tradiciones orales, absolutamente rechazables desde el punto de vista histórico. Del mismo modo, otros censores y anotadores del Nobiliario calificaron el contenido de nuestro relato de «patrañas», «patraña antigua», «patrañas de vizcaínos», «suceso fabuloso» $\mathrm{y}$ «cuento».

Frente a estas opiniones están las de dos anotadores de la edición castellana: Manuel de Faria y Félix Machado, marqués de Montebelo. Ambos desaprueban la omisión efectuada en la edición portuguesa, que el primero tradujo literalmente, justificando su censura con diferentes argumentos.

10 Pedro Jerónimo de APONTE, nota marginal en el ms. 9/2238 de la Academia de la Historia, fol. 1r.

11 Juan SAlgado de ARAujo, Sumario de la familia ilvstrissima de Vasconcelos (Madrid, 1638), fols. 2v-4r.

12 Luis de SAlazar y CASTro, Historia genealógica de la Casa de Haro (Madrid: Imp. Vicente Rico, 1920), pp. 118-119. 
Aunque está de acuerdo con los eruditos que lo hacían derivar de antiguas tradiciones, Faria disiente de ellos en lo que se refiere a su valoración e importancia. "Son memorias dignas de perpetuidad», afirma, y aduce la necesidad de su conservación como fuente de conocimiento de las mentalidades de los antepasados. Machado sostiene que los relatos eliminados referían acontecimientos históricos: la causa de que su historicidad sea difícilmente reconocible es la deformación y el deterioro provocados por un largo proceso de tradición oral. Tampoco Faria descarta su fondo histórico, y justifica esta posibilidad proponiendo dos interpretaciones.

La perspectiva de la primera contempla a «la muger del pie de cabra» y a doña Mariña -en el título LXXIII del Livro- como monstruos, prodigios de la naturaleza, de los que conviene guardar memoria. Muchos autores, desde Plutarco a Olao Magno, habían tratado de ellos; incluso, algunos eruditos portugueses del Quinientos, como Jerónimo Osorio o Diego de Couto, referían testimonios semejantes. La idea no era nueva: desde los primeros testimonios de la leyenda, este tipo de mujeres sobrenaturales y monstruosas había servido para ejemplificar algunos de los misteriosos fenómenos y portentos del mundo natural.

Su segunda tentativa de argumentación coincide con la última «interpretación» que se puede rastrear en estos siglos. Los dos anotadores acuden a la idea de la intervención manifiesta y casi cotidiana de fuerzas sobrenaturales maléficas en las vidas humanas. Félix Machado justifica tal presencia por la práctica de las «artes mágicas»; desde la misma perspectiva, Manuel de Faria enumera, confusa y desordenadamente, ciertas apreciaciones, extraídas de un texto cuya procedencia silencia.

Unos cuarenta años antes de que estas consideraciones aparecieran en la edición castellana, el licenciado Diego de Yepes, capellán del Hospital de la Santa Cruz de Toledo, había compuesto una Censura sobre el contenido del relato. Dicha Censura, que figura como adición en un grupo de manuscritos castellanos del Livro, pudo ser la fuente de la confusa nota de Faria, y lo es, sin duda, de buena parte del capítulo XV del IV libro de la Curiosa y oculta Filosofía del P. Nieremberg, publicada en Madrid en $1643^{\prime \prime}$.

Yepes empieza y concluye con declaraciones sobre la finalidad docente de su escrito, en relación con los problemas que puede plantear a los lectores el contenido del relato. Argumenta en favor de su veracidad - justificando así los criterios historiográficos del conde don Pedro- y previene a sus destinatarios en contra de un precipitado re-

1: Juan Eusebio Nieremberg, Curiosa y oculta Filosofía (Madrid. 1643), IV, cap. 15. 
chazo de historias como éstas que, como intenta demostrar, son fantásticas sólo en apariencia. Así, al menos desde nuestra perspectiva, podemos contemplar su Censura como una respuesta a los «rechazos» de algunos de esos lectores, cuyas opiniones conocemos. Sus argumentos están respaldados por la autoridad de una larga tradición de «teólogos y canonistas» y por la propia experiencia: los materiales eruditos se funden con creencias populares, los escritores cristianos con los paganos, la mitología clásica con la Escolástica, la historia natural con la Biblia...

En definitiva, Yepes y Nieremberg no son sino dos representantes más de la serie de clérigos y monjes que, desde la Edad Media, habían utilizado la leyenda para prevenir a sus lectores y a toda la comunidad de fieles, a través de la predicación, en contra del pecado y de las continuas trampas e inesperados ardides del diablo.

Gran parte de los principios expuestos en la Censura muestran significativos paralelismos con algunos de los manejados en tratados, manuales de inquisidores o actas judiciales de procesos contra la posesión diabólica y la brujería, aunque Yepes no aluda explícitamente a ellas. Además, algunas de sus fuentes - como el Formicarius, de Johannes Nider, el Malleus maleficarum, de Jacobo Sprenger y Enrique Institor, y el Tractatus de hereticis et sortilegiis, de Paulus Grillandus - trataban amplia o exclusivamente del tema, y contribuyeron a configurar la idea que se tenía de él. A través de ellas, Yepes pudo explicar un fenómeno distinto, pero que desde su perspectiva respondía a los mismos principios: el estereotipo de la bruja y del sabbat que circulaba desde tiempo atrás comprendía, además de otras, ideas similares.

La última etapa de la «historia» de nuestro relato se inicia con dos publicaciones portuguesas del segundo tercio del siglo XIX, debidas a la iniciativa de Alexandre Herculano: la novela gótica $A$ Dama Pé de Cabra (Lisboa, 1843) ${ }^{14}$ y la primera transcripción íntegra del códice del Livro de linhagens del Archivo de la Torre do Tombo y de un fragmento de la Biblioteca del Palacio de Ajuda, que no contiene el título IX (Lisboa, 1856) ${ }^{15}$.

Desde el siglo XIII la leyenda venía inspirando fragmentos de obras de carácter literario. Si en los primeros testimonios suele aparecer su-

14 Alexandre Herculano, Lendas e narrativas, revisão de Vitorino Nemésio, verificação do texto e notas por António C. Lucas (Venda Nova-Amadora: Livraria Bertrand, 1970), II.

15 Livro das linhagens do conde D. Pedro (Lisboa: Academia das Ciências, 1856), pp. $184-229$ y $230-390$. 
bordinada a objetivos de índole genealógica, en el período contemporáneo prevalece la intención puramente recreadora o «artística».

Así sucede en $A$ Dama Pé de cabra, donde Herculano aprovecha el «esqueleto narrativo» proporcionado por el relato del título IX y lo somete a un determinado "tratamiento» de recreación literaria. En general hace uso de amplificaciones y repeticiones; en ocasiones sustituye componentes del relato fuente; raras veces omite, y cuando lo hace se trata casi siempre de transformaciones o de redistribuciones de motivos, presentes en otros lugares del sintagma narrativo.

También se sirvió de conocidos tópicos y de materiales y recursos del arte narrativo tradicional y del romántico, sobre todo del relato terrorífico. La narración está presentada y actualizada mediante la intervención de un juglar, cuyo discurso valorativo reproduce con habilidad el lenguaje formulaico y los tópicos habituales en narraciones populares y épico-juglarescas. Las sucesivas introducciones de unos relatos en otros es otro viejo recurso utilizado por Herculano para intercalar las adiciones más significativas que la novela presenta con respecto al relato fuente: la Entrevista de don Diego con el abad y, dentro de ella, la Historia de la condesa y Astrigildo.

La actuación de fuerzas sobrenaturales cobra gran relieve, hasta constituir el eje o paradigma temático fundamental de la novela. Con estos y otros procedimientos se crea un ambiente de misterio y asombro, certeramente distendido mediante un tono de desenfado y frecuentes rasgos de humor.

La segunda iniciativa de Herculano - la edición del códice de la Torre do Tombo- fue decisiva para el conocimiento y la difusión del relato, que, por haberse suprimido en las dos adaptaciones del siglo XVII, sólo había circulado hasta ese momento en copias manuscritas. Más recientemente, el profesor Mattoso ha editado la reconstrucción de la refundición de 1380-1383 (Lisboa, 1980) ${ }^{16}$. No existe ninguna edición de las versiones del Livro a nuestro idioma, único al que ha sido traducido.

A partir de la edición de Herculano, Menéndez Pelayo tradujo el relato al castellano '. Esta traducción ha sido muy difundida, por ser la que, en general, se ha venido manejando: reproducida o adaptada en castellano y, con mayor o menor fidelidad, en vasco, figura en libros de lectura infantil y en posteriores estudios sobre diversos temas (historia de Vizcaya, mitología vasca, etc.).

Litro de linhagens do conde don Pedro (Lisboa: Academia das Ciências, 1980), 2 vols.

Marcelino Menéndez Pelayo, Antología de poetas líricos castellanos, ed. de Enrique Sánchez Reyes (Santander: CSIC. 1964), VI, pp. 364-366. 
En consonancia con la creciente atención que, sobre todo a partir del Romanticismo, se presta a la Edad Media, al folklore y a las tradiciones populares, desde que se publicó dicha traducción asistimos a una lenta fase expansiva de referencias, generalmente marginales, sobre el tema. Pertenecen a un heterogéneo conjunto de estudios de carácter filológico, antropológico, historiográfico, etc., donde generalmente se reconoce la autoridad de José Miguel de Barandiarán ${ }^{18}$ y de Julio Caro Baroja ${ }^{19}$, quienes sitúan la versión dentro del ciclo mítico de Mari y las lamias vascas.

Y por lo que a la leyenda se refiere, han tenido notable repercusión, entre otros, algunos trabajos de Georges Dumézil ${ }^{20}$, Jacques Le Goff y Emmanuel Le Roy Ladurie ${ }^{21}$, Claude Lecouteux ${ }^{22}$, Laurence HarfLancner ${ }^{23}$, etc. Ciñéndonos a los límites y objetivos de este artículo, podemos concluir enmarcando las realizaciones llevadas a cabo en este terreno en tres áreas:

- Elaboración de corpus parciales, definidos de acuerdo con criterios geográficos y cronológicos.

- Análisis de la leyenda, tratando de describir su organización interna específica y formulando diversas propuestas de definición de la misma.

- Interpretaciones sobre su significación y funciones.

Vestigio, según algunos, de las funciones de las llamadas diosas indoeuropeas trivalentes, la leyenda ha conservado los principios básicos mencionados, pero también ha podido ser utilizada desde diferentes perspectivas, incorporándose a las variadas situaciones y contextos culturales en que la hemos podido encontrar.

\section{J. RAMÓN PRIETO LASA}

Universidad del País Vasco

\footnotetext{
18 Ver José Miguel de Barandiarán, Mitología vasca (Madrid: Minotauro, 1960), pp. $91-99$.

19 Ver Julio Caro Baroja, «Las lamias vascas y otros mitos», Algunos mitos españoles (Madrid: Centro, ${ }^{3} 1974$ ), pp. 33-72.

20 Georges DumÉzil, Le problème des Centaures (Paris: Paul Geuthner, 1929).

21 Jacques Le Goff et Emmanuel Le Roy LAduRIE, «Mélusine maternelle et défricheuse», Annales. Économies, Sociétés, Civilisations (mai-aôut 1971), pp. 587-622.

22 Claude Lecouteux, Mélusine et le Chevalier au Cygne (Paris: Payot, 1982) y "La structure des légendes mélusiniennes», Annales. Économies, Sociétés, Civilisations (mars-avril 1976), pp. 294-306.

23. Laurence HARF-LANCNER, Les fées au Moyen Age. Morgane et Mélusine. La naissance des fées (Paris: Librairie Honoré Champion, 1984).
} 
El artículo resume un estudio sobre el significado y la tradición de un relato mítico, realizado desde una perspectiva sincrónica (mediante el análisis de cuarenta versiones europeas de la misma leyenda) y diacrónica (observando las diferentes «manipulaciones» de que ha sido objeto a lo largo de su historia). Se trata de un relato medieval, perteneciente al ciclo mítico de Melusina, cuyos sucesivos héroes son Diego López e Íñiguez Guerra, señores de Vizcaya cuarto y quinto, según la genealogía de los Haro contenida en el título IX del Livro de linhagens, compuesto entre 1340 y 1344 por Pedro de Barcelos.

The article present sums up a research on the meaning and the tradition of a mythical tale, carried out under two different outlooks: synchronic (through the analysis of 40 European renderings of the same legend) and diachronic (by considering the different «manipulations» of the tale throughout history). It is a medieval story whithin the mythical cycle of Mélusine whose heroes are Diego López and Íñiguez Guerra, the fourth and fifth Lords of Biscay according to the geneaology of the Haro Family, held in chapter IX of the Livro de linbagens, that was written between 1340 and 1344 by Pedro de Barcelos. 